\title{
The Effects of Ginger on Gallbladder Motility in Healthy Male Humans
}

\author{
Seng-Kee Chuah, Keng-Liang Wu, ${ }^{*}$ Wei-Chen Tai and Chi-Sin Changchien
}

Division of Hepatogastroenterology, Department of Internal Medicine, Chang Gung Memorial Hospital, Kaohsiung Medical Center, Chang Gung University, College of Medicine, Kaohsiung, Taiwan

\section{Background/Aims}

Ginger has been used to treat a number of diseases including those affecting the digestive tract. This study was aimed to investigate the effects of ginger on gallbladder volume and gastrointestinal sensation in healthy male subjects.

\section{Methods}

Nineteen healthy male volunteers (age $21.3 \pm 3.9$ years, body mass index $21.6 \pm 1.9 \mathrm{~kg} / \mathrm{m}^{2}$ ) were studied on 2 occasions in a double blind randomized crossover design. After ingesting ginger $(1,200 \mathrm{mg})$ or placebo capsules (starch), abdominal ultrasound was used to measure the gallbladder volume (calculated from gallbladder width, depth and diameter) and ejection fraction following a standard test meal. Gastrointestinal symptoms were also recorded at regular intervals by visual analogue scales.

\section{Results}

There were no differences in gallbladder volume or ejection fraction between ginger and placebo. Abdominal symptoms of bloating, fullness, nausea, discomfort and hunger was not different between the 2 occasions.

\section{Conclusions}

Ginger $(1,200 \mathrm{mg})$ may not affect gallbladder ejection fraction and possible relevant abdominal symptoms in healthy male human subjects.

(J Neurogastroenterol Motil 2011;17:411-415)

Key Words

Abdomen; Gallbladder; Ginger; Ultrasonography

\section{Introduction}

Ginger (Zingiber officinale) has been used to treat a number of diseases; including those affecting the digestive tract. ${ }^{1-5}$ It has been a household remedy for dyspepsia, flatulence, colic and diar- rhea, as well as being used in foods as a spice. Pharmacological effects of ginger on the gastrointestinal tract, such as the stimulation of gastrointestinal motility were widely reported. ${ }^{6-10}$ In our previous studies, we found ginger accelerated gastric motility such as emptying and antral contractions in healthy volunteers ${ }^{4}$ and in patients with functional dyspepsia. ${ }^{11}$ Reports on the issue

Received: April 15, 2011 Revised: June 11, 2011 Accepted: June 13, 2011

(c) This is an Open Access article distributed under the terms of the Creative Commons Attribution Non-Commercial License (http://creativecommons. org/licenses/by-nc/3.0) which permits unrestricted non-commercial use, distribution, and reproduction in any medium, provided the original work is properly cited.

*Correspondence: Keng-Liang Wu, MD

Division of Hepatogastroenterology, Department of Internal Medicine, Chang Gung Memorial Hospital, Kaohsiung Medical Center, Chang Gung University, College of Medicine, 123, Ta-Pei Road, Niao-Sung District, Kaohsiung City 83301, Taiwan Tel: +886-7-731-7123 (ext.8301),Fax: +886-7-732-2402, E-mail: kengliang_wu@yahoo.com.tw

Financial support: None.

Conflicts of interest: None. 
of effects of ginger to the other digestive organ such as biliary system were relatively scarce. By far, ginger was reported to increase bile secretion, ${ }^{12,13}$ and could be correlated with the formation of gallbladder stones, but without citing a rationale. ${ }^{14}$ So far, there is no study reports on the effect of ginger on gallbladder emptying in human or animal. We therefore conducted current study to investigate the effect of ginger on gallbladder ejection fraction by evaluating gallbladder volume using trans-abdominal ultrasound and on relevant gastrointestinal symptoms using questionnaires.

\section{Materials and Methods}

\section{Subjects}

Nineteen healthy male volunteers (age $21.3 \pm 3.9$ years, body mass index $21.6 \pm 1.9 \mathrm{~kg} / \mathrm{m}^{2}$ ) were recruited. None of them had a history of gastrointestinal disease, gallbladder stone, previous abdominal surgery using regular medications, consuming more than $20 \mathrm{~g}$ alcohol daily and smoking. All subjects gave written, informed consent, and the protocol was approved by the Research Ethics Committee of the Chang Gung Memorial Hospital (Kaohsiung).

\section{Experimental Procedure}

Each subject was studied on 2 occasions, separated by at least 7 days, in randomized, double-blind order. Subjects stopped drinking alcohol for 48 hours before each study day. After fasting 8 hours from solids and liquids, they ingested 3 capsules containing a total of 1,200 mg powdered ginger root (Ginger Root; Nature's Way Products Inc, Springville, UT, USA), or a match-

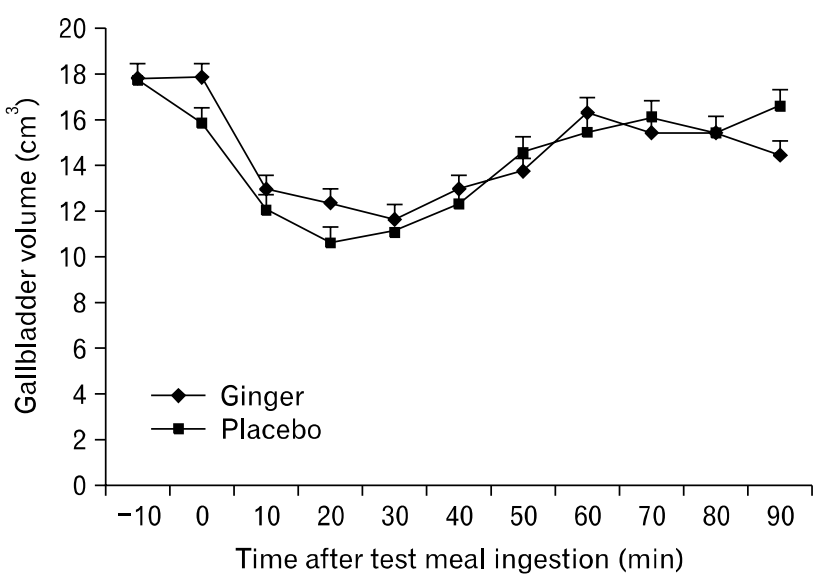

Figure 1. There is no difference on gall bladder volume between ginger and placebo during postprandial 90 minutes $(P>0.05)$. ing placebo containing starch, taken with $50 \mathrm{~mL}$ of water. One hour later, they consumed a $500 \mathrm{~mL}$ nutrient liquid test meal (drinking time, 5 minutes [ $\mathrm{T}=-5$ to 0 minutes]; commercial meat soup [chicken and corn soup] containing $2.6 \mathrm{~g}$ protein, 2.6 $\mathrm{g}$ fat and $21.2 \mathrm{~g}$ carbohydrate [118.6 kcal]; United Kanboo Co, Ltd, Taipei, Taiwan). The soup was boiled and subsequently cooled to $37^{\circ} \mathrm{C}$ before ingestion.

\section{Measurements of Gallbladder Volume}

Measurements of gallbladder volume were performed with the subject seated in a comfortable chair, leaning slightly backward (about $100^{\circ}$ ), using a Toshiba SSA-340A CL Ultrasound Machine (Toshiba Co, Ltd, Japan) with a 3.5 MHz convex array probe. The transducer was positioned vertically to visualize. All gallbladder volumes were calculated by using the formula for volume $\left(\mathrm{cm}^{3}\right)=0.52 \times$ (length $[\mathrm{cm}] \times$ width $[\mathrm{cm}] \times$ height $[\mathrm{cm}]) .{ }^{15}$ Measurements of gallbladder width, depth and diameter were obtained at baseline ( $\mathrm{T}=-10$ minutes), and 10 minutes interval from $\mathrm{T}=0$ to 90 minutes. Ejection fraction of the gallbladder at each postprandial time point was calculated as follows: $\mathrm{EF}(\%)=([$ fasting gallbladder - postprandial gallbladder volume]/fasting gallbladder volume $) \times 100$. $^{16,17}$

\section{Measurement of Abdominal Symptoms}

Abdominal symptoms (abdomen fullness, nausea, abdomen discomfort, bloating and hunger) were assessed at baseline ( $\mathrm{T}=$ -10 minutes) and at 10 minute intervals from $\mathrm{T}=0$ to $90 \mathrm{mi}-$ nutes, using $10 \mathrm{~cm}$ visual analogue scales. ${ }^{18}$

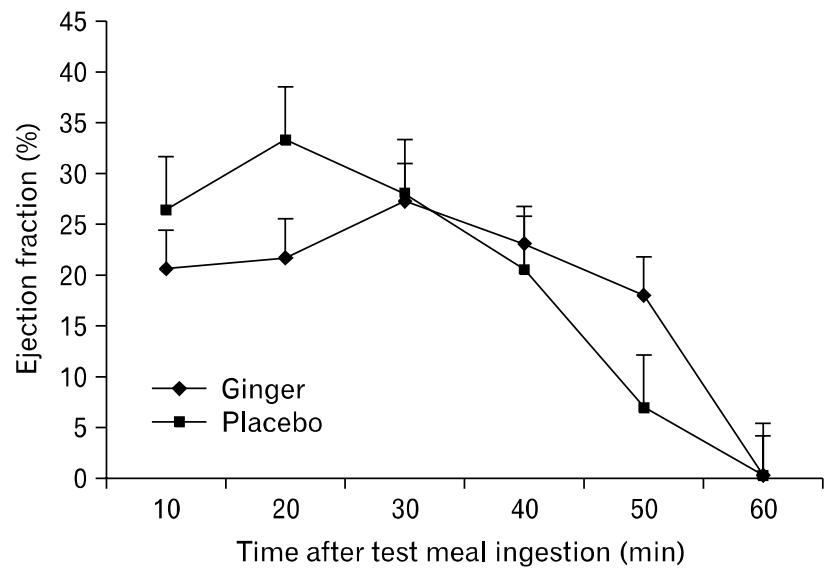

Figure 2. There is no significant difference between gall bladder ejection fraction between ginger and placebo during postprandial 60 minutes $(P>0.05)$. 


\section{Statistical Methods}

The data was analyzed by Statistical Package for Social Sciences (SPSS) 13.0 version (SPSS Inc, Chicago, IL, USA). The curves for gallbladder volume, ejection fraction and gastro-
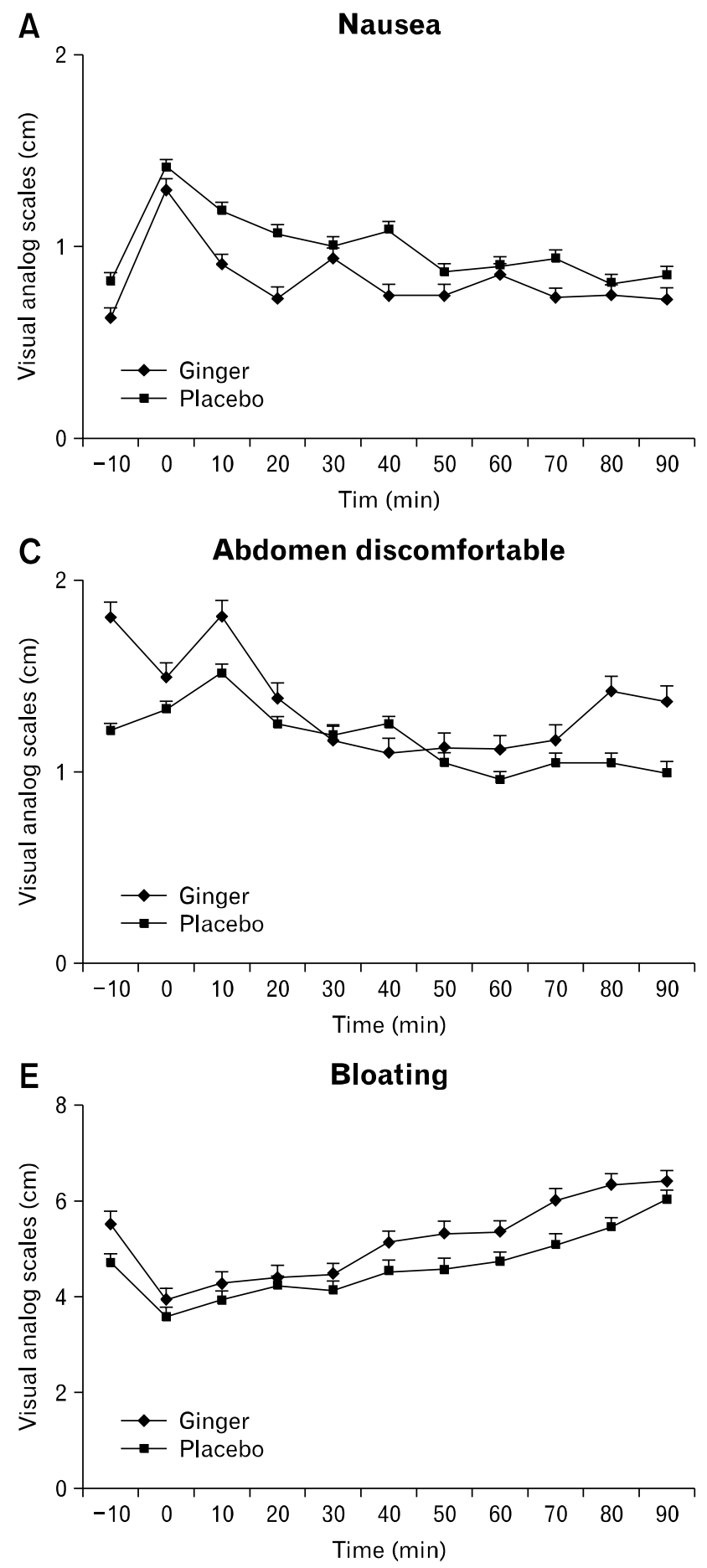

intestinal sensation scores, were compared using repeated measures analysis of variance. Ejection fraction of gallbladder and gastrointestinal sensation scores were compared using Student's paired $t$ tests. Results are shown as means $\pm \mathrm{SD}$. $P$-values $<$ 0.05 were considered significant.
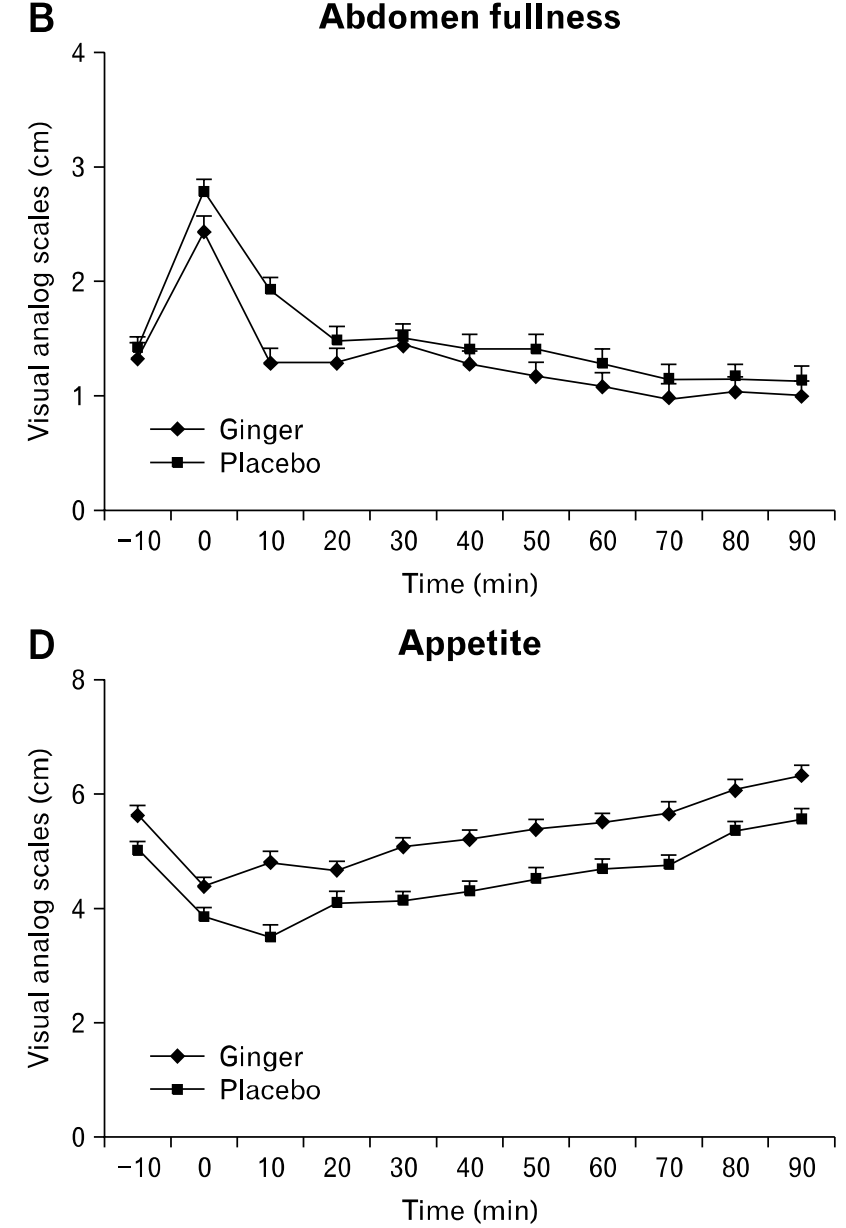

Figure 3. There is not significantly different between 2 sections for possible relevant abdominal symptoms such as (A) nausea, (B) abdomen fullness, (C) abdomen discomfort, (D) hunger and (E) abdomen bloating. 


\section{Results}

The mean $\pm \mathrm{SD}$ of initiatory gallbladder volume was $17.4 \pm$ $7.0 \mathrm{~cm}^{3}$, then gradually decreased to the smallest gallbladder volume which was $11.1 \pm 4.5 \mathrm{~cm}^{3}$ post test meal 30 minutes and returned to plateau after 60 minutes. There were no differences in gall bladder volume (Fig. 1) or ejection fraction between ginger and placebo (Fig. 2).

Abdominal hunger sensation was increased correlating with time in both 2 groups. No significant difference existed between the 2 study days regarding the abdominal symptoms such as abdomen bloating, fullness, nausea, abdomen discomfort and hunger (Fig. 3). All volunteers tolerated the study well and there were no adverse events reported afterwards.

\section{Discussion}

Ginger has been recognized as having a digestive stimulant action. ${ }^{1-5}$ We had proven the enhanced gastric motility with ginger in normal volunteers and patients suffering from functional dyspepsia. However, the effect of ginger on other digestive system such as biliary system, especially the gallbladder motility is an interesting issue and rarely explored in the literature. Bhat et $\mathrm{al}^{19}$ conducted a study of inserting a polyethylene cannula into the common bile duct of rats, and observed that ginger increased the secretion of bile. Platel and Srinivasan ${ }^{20}$ reported the digestive stimulant action of ginger to be probably exerted through stimulation of the liver to produce and secrete bile rich in bile acids, and increased bile acid secretion concomitant with the increased bile flow rate, which also played a very important role in fat digestion and absorption. However, they did not measure gallbladder motility in their study. Ginger did not induce any effect on gallbladder volume of healthy human in our current study and this observation of ginger not increasing ejection fraction of the gallbladder after test meal may be explained by the report explaining the enhanced bile flow to be probably exerted through stimulation of the liver to produce and secrete more bile. Ginger may directly stimulate liver to secrete more bile juice, but does not accelerate gallbladder ejection fraction. We did not directly monitor gallbladder motility, therefore we could not exclude the possibility that ginger has any effect on gallbladder motility and further study is needed to clarify this issue.

We used 1,200 mg ginger as testing dose and 60 minutes for duration in our study, because Lien et $\mathrm{al}^{21}$ reported $1,200 \mathrm{mg}$ ginger had a reduction in nausea induced by circular vection and Zick et $\mathrm{al}^{22}$ reported ginger conjugates began to appear $30 \mathrm{mi}$ nutes after oral dosing, reaching their $\mathrm{T}_{\max }$ between 45 to 120 minutes, with elimination half-lives ranging from 75 to 120 minutes at the dose of $2.0 \mathrm{~g}$. Although we did not study higher dose of ginger for gallbladder emptying but 1,200 mg had enough effect on gastrointestinal motility as previous studies. ${ }^{4,11,21}$

There were no differences between ginger and placebo on the sensation scales for abdominal bloating, fullness, nausea, abdominal discomfort, hunger and desire to eat. This was consistent to our previous reports on gastric emptying. Firstly, the volunteers were healthy and did not suffer from any gastrointestinal symptoms and the test meal we used was relatively low calori product $(120 \mathrm{kcal})$. The increases noted in appetite and bloating after meal ingestion were not significantly different. Secondly, the subjects in current study were healthy volunteers without dyspeptic syndromes, so it could not cause any effort on abdomen sensation.

However, this study encounters limitations. First, we used an aqueous extract of ginger instead of acetone extract. The acetone extract is reported to have more potent cholagogic effect. ${ }^{23}$ Second, we did not measure bile flow through the common bile duct in our study and could not confirm whether the flow was indeed stimulated by ginger. Third, the calori and proportion of fat in test meal were very low, so it was hard to induce more bile secretion differently. Forth, we did not evaluate the adequate doses of ginger for dose dependent study.

Further studies measuring the trans-sphincter flow to get more information about gallbladder motility may be helpful to clarify this issue. Ultrasound to measure gallbladder volume is difficult and technique-dependent while scintigraphy is still the standard method to measure gallbladder emptying. The effect of ginger on gallbladder in human has never been reported. We used 1,200 mg as from our previous study on gastric emptying but we may need more information regarding the ginger dosage to clarify its effect on gallbladder. In conclusion, ginger $(1,200$ $\mathrm{mg}$ ) may not affect gallbladder motility and the relevant abdominal symptoms in healthy male human subjects. ${ }^{4}$

\section{References}

1. Gruenwald J, Brendler T, Jaenicke C. PDR for herbal medicines. Montvale, New Jersey: Medical Economics Company 2000:212213.

2. Cupp MJ. Toxicology and clinical pharmacology of herbal products. Totowa, New Jersey: Humana Press 2000:11-30.

3. Capasso F, Gaginella TS, Grandolini G, Izzo AA. Phytotherapy: A 
quick reference to herbal medicine. Heidelberg: Springer-Verlag 2003:372.

4. Hu ML, Rayner CK, Wu KL, et al. Effect of ginger on gastric motility and symptoms of functional dyspepsia. World J Gastroenterol 2011;17:105-110.

5. Shariatpanahi ZV, Taleban FA, Mokhtari M, Shahbazi S. Ginger extract reduces delayed gastric emptying and nosocomial pneumonia in adult respiratory distress syndrome patients hospitalized in an intensive care unit. J Crit Care 2010;25:647-650.

6. Yamahara J, Huang QR, Li YH, Xu L, Fujimura H. Gastrointestinal motility enhancing effect of ginger and its active constituents. Chem Pharm Bull (Tokyo) 1990;38:430-431.

7. Satoh K, Kase Y, Hayakawa T, Murata P, Ishige A, Sasaki H. Dai-kenchu-to enhances accelerated small intestinal movement. Biol Pharm Bull 2001;24:1122-1126.

8. Shibata C, Sasaki I, Naito H, Ueno T, Matsuno S. The herbal medicine Dai-Kenchu-Tou stimulates upper gut motility through cholinergic and 5-hydroxytryptamine 3 receptors in conscious dogs. Surgery 1999;126:918-924.

9. Murata P, Hayakawa T, Satoh K, Kase Y, Ishige A, Sasaki H. Effects of Dai-kenchu-to, a herbal medicine, on uterine and intestinal motility. Phytother Res 2001;15:302-306.

10. Sharma SS, Gupta YK. Reversal of cisplatin-induced delay in gastric emptying in rats by ginger (Zingiber officinale). J Ethnopharmacol 1998;62:49-55.

11. Wu KL, Rayner CK, Chuah SK, et al. Effects of ginger on gastric emptying and motility in healthy humans. Eur J Gastroenterol Hepatol 2008;20:436-440.

12. Yamahara J, Miki K, Chisaka T, et al. Cholagogic effect of ginger and its active constituents. J Ethnopharmacol 1985;13:217-225.

13. Platel K, Rao A, Saraswathi G, Srinivasan K. Digestive stimulant ac- tion of three Indian spice mixes in experimental rats. Nahrung 2002;46:394-398.

14. Rister R, Klein S, Riggins C. The complete German commission E monographs: Therapeutic guide to herbal medicines. Austin, Tx: American Botanical Council 1998:135-136.

15. Sari R, Balci MK, Coban E, Karayalcin U. Sonographic evaluation of gallbladder volume and ejection fraction in obese women without gallstones. J Clin Ultrasound 2003;31:352-357.

16. Murray FE, Stinchcombe SJ, Hawkey CJ. Effect of indomethacin and misoprostol on fasted gallbladder volume and meal-induced gallbladder contractility in humans. Dig Dis Sci 1992;37:1228-1231.

17. Everson GT, Braverman DZ, Johnson ML, Kern F Jr. A critical evaluation of real-time ultrasonography for the study of gallbladder volume and contraction. Gastroenterology 1980;79:40-46.

18. Sepple CP, Read NW. Gastrointestinal correlates of the development of hunger in man. Appetite 1989;13:183-191.

19. Bhat GB, Sambaiah K, Chandrasekhara N. The effect of feeding fenugreek and ginger on bile composition in the albino rat. Nutr Rep Int $1985 ; 32: 1145-1152$.

20. Platel K, Srinivasan K. Digestive stimulant action of spices: a myth or reality? Indian J Med Res 2004;119:167-179.

21. Lien HC, Sun WM, Chen YH, Kim H, Hasler W, Owyang C. Effects of ginger on motion sickness and gastric slow-wave dysrhythmias induced by circular vection. Am J Physiol Gastrointest Liver Physiol 2003;284:G481-G489.

22. Zick SM, Djuric Z, Ruffin MT, et al. Pharmacokinetics of 6-ginger$\mathrm{ol}$, 8-gingerol, 10-gingerol, and 6-shogaol and conjugate metabolites in healthy human subjects. Cancer Epidemiol Biomarkers Prev 2008;17:1930-1936.

23. Yamahara J, Miki K, Chisaka T, et al. Cholagogic effect of ginger and its active constituents. J Ethnopharmacol 1985;13:217-225. 